\title{
REGIOSELECTIVE 2,4-DINITROARENE REDUCTION AS A PATH TO VARIOUS HETEROCYCLIC COMPOUNDS AND POTENT QUINONE REDUCTASE 2 (NQO2) INHIBITORS
}

\author{
A.I. Maksutova, M.D. Tsymliakov \\ Department of Chemistry, Lomonosov Moscow State University, \\ 119234, Russia, Moscow, Leninskie Gory St., 1 \\ E-mail:anita.maksutova@gmail.com
}

DOI: 10.19163/MedChemRussia2021-2021-404

Two novel regioselective reduction methods are proposed in this work: both are versatile, scalable and preparative. 2-amino-4-nitroanilines open up the way to various heterocyclic systems, such as quinoxalinones, 4,7-disubstituted isatins, and (thio)benzimidazole(on)es, which can lead to a vast variety of biologically active compounds (Figure 1).

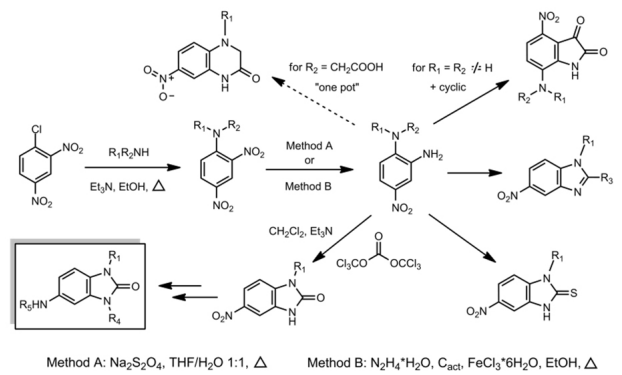

Fig. 1. Obtaining different heterocyclic systems using products of regioselective reduction

For example, 5-substituted benzimidazolones can express a high binding affinity to NQO2 enzyme according to molecular modeling studies, carried out in this work (Figure 2). NQO2 inhibition is important in treatment of such diseases as glaucoma, Alzheimer's disease, cancer, etc.
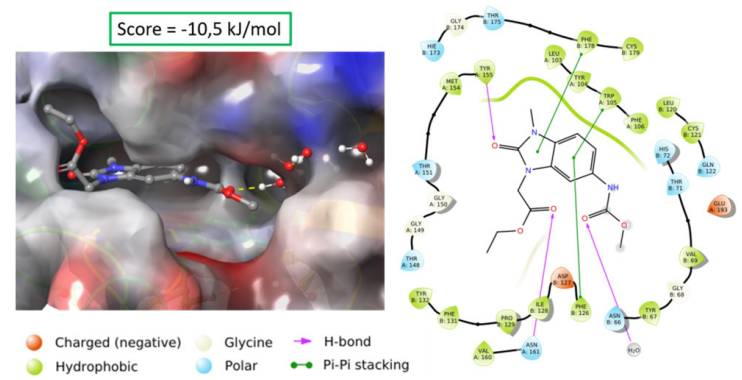

Fig. 2. Molecular docking example: NQO2 active site binding and pharmacophore model This work was supported by the Russian Foundation for Basic Research (Project 20-03-00915) 